\title{
A Esclerose Lateral Amiotrófica como Doença Autoimune
}

\author{
The Sporadic Amyotrophic Lateral Sclerosis as Autoimmune \\ Ronald Pallotta ${ }^{1}$, Antonio Andrade ${ }^{2}$, Ohana Caroline Machado Bispo ${ }^{3}$
}

\section{RESUMO}

Introdução. A Esclerose lateral amiotrófica (ELA) é uma doença caracterizada pela degeneração progressiva dos neurônios motores (NM). Atualmente, a participaçáo da resposta imune tem sido alvo de pesquisas que indicam o componente autoimune no desenvolvimento da ELA. Método. Este trabalho, através de uma revisão da literatura, buscou avaliar a participação da autoimunidade na fisiopatologia da ELA esporádica. Resultados. Foram encontrados 50 artigos e, após critérios de exclusão aplicados, resultaram em 11 artigos, sendo $3 \mathrm{em}$ modelos animais e 8 estudos com humanos. As três provas para o estabelecimento se uma doença humana é autoimune foram analisadas para ELA. Conclusáo. Os achados dos estudos levantados indicam a participação de uma reação autoimune na ELA esporádica. Novos estudos envolvendo auto-anticorpos e células T auto-reativas devem ser realizados. E a partir disto novas estratégias terapêuticas podem ser traçadas.

Unitermos. Esclerose Amiotrófica Lateral, Doenças auto-imunes, Auto-imunidade.

Citaçáo. Pallotta R, Andrade A, Bispo OCM. A Esclerose Lateral Amiotrófica como Doença Autoimune.

\begin{abstract}
Introduction. Amyotrophic lateral sclerosis (ALS) is a disease characterized by progressive degeneration of motor neurons (MN). Currently, the participation of the immune response has been the subject of research indicating the autoimmune component in the development of ALS. Method. This paper, through a literature review sought to evaluate the participation of autoimmunity in the pathophysiology of sporadic ALS. Results. There were 50 articles and after exclusion criteria applied, resulting in 11 articles, 3 in animal models and 8 studies in humans. The three tests for establishing whether a human disease is autoimmune were analyzed for ALS. Conclusion. The findings of the studies surveyed indicate the involvement of an autoimmune reaction in sporadic ALS. Further studies involving autoantibodies and autoreactive $\mathrm{T}$ cells should be performed. And from this new therapeutics strategies can be traced.
\end{abstract}

Keywords. Amyotrophic Lateral Sclerosis, Autoimmune diseases, Autoimmunity.

Citation. Pallotta R, Andrade A, Bispo OCM. The Sporadic Amyotrophic Lateral Sclerosis as Autoimmune.
Trabalho realizado na Escola Bahiana de Medicina e Saúde Pública - Fundaçáo Bahiana de Desenvolvimento das Ciências, Salvador-BA, Brasil. 1.Hematologista, Professor Assistente da EBMSP-FBDC, núcleo de oncohematologia e terapia celular, Salvador- Bahia, Brasil.

2.Neurologista, Professor Titular da EBMSP-FBDC, núcleo de neurologia, Salvador-BA, Brasil.

3.Estudante de Medicina da EBMSP-FBDC, Salvador-BA, Brasil.
Endereço para correspondência: Ronald Pallotta Alameda dos Jasmins $n^{\circ} .88$, apto 1902 - Cidade Jardim CEP 40296-200, Salvador-BA, Brasil.

E-mail: tmobahia@yahoo.com.br 


\section{INTRODUÇÃO}

A Esclerose Lateral Amiotrófica (ELA) foi descrita em 1874 por Charcot $^{1}$. É uma doença caracterizada pela degeneração progressiva dos neurônios motores ${ }^{2}$. O termo amiotrófica está relacionado à atrofia muscular, fraqueza e fasciculaçôes, que são indicativos do comprometimento do neurônio motor inferior. Os achados clínicos de hiperreflexia, sinal de Hoffman, sinal de Babinski e clônus relacionam-se ao comprometimento do neurônio motor superior ${ }^{1}$.

A taxa de incidência da ELA está entre 1 a 5 casos para 100.000 habitantes e atinge preferencialmente homens $^{3,4}$. Sendo que $20 \%$ dos casos estão relacionados a fatores genéticos (ELA familiar) e $80 \%$, não (ELA esporádica). A sobrevida média em cinco anos é de $25 \%{ }^{2}$.

O diagnóstico clínico da ELA é provavelmente correto em mais de $95 \%$ dos casos. Este pode ser auxiliado pela eletromiografia para pesquisa de acometimento do neurônio motor inferior e pela ressonância nuclear magnética com espectroscopia e a estimulação magnética do córtex que pesquisa o comprometimento do neurônio motor superior ${ }^{1}$.

A patogenia da ELA é dita multifatorial e, apesar dos estudos de diversas teorias, que não são necessariamente excludentes, sua etiologia não é bem elucidada. Algumas das teorias já documentadas são a mutação na enzima $\mathrm{Cu} / \mathrm{Zn}$ da Superóxido dismutase 1 (SOD1) que pode levar a toxicidade pelo aumento de superóxido; o aumento do glutamato que leva a excitoxicidade com o acúmulo de cálcio intracelular; fatores ambientais (infecções virais e estudos epidemiológicos); o acúmulo de neurofilamentos; a ativação da micróglia e das células $\mathrm{T}$ e a presença de autoanticorpos. Atualmente, este componente imunológico tem sido alvo de pesquisas que indicam o componente imune ou mesmo auto-imune no desenvolvimento da ELA ${ }^{1-7}$.

Alguns trabalhos já elucidaram que a auto-imunidade pode ter participação na patogenecidade da ELA. Uma das teorias baseia-se no fato de que as células da micróglia passam a reconhecer antígenos autólogos dos neurônios motores, levando à ativação das células T CD4+, ao recrutamento de células inflamatórias, à diferenciação dos linfócitos $\mathrm{B}$, com produção de imunoglobulinas específicas contra auto-antígenos ${ }^{2}$. Outros estudos já evi- denciaram a presença de anticorpos IgG contra os canais de cálcio voltagem dependentes, o que pode interferir na concentração de cálcio intracelular, levando a degeneração do neurônio motor ${ }^{1,6,7}$.

Assim esse trabalho tem como objetivo avaliar a participação da auto-imunidade na fisiopatologia da ELA.

\section{MÉTODO}

Este é um estudo descritivo baseado na revisão da literatura. Foram selecionados artigos do período de janeiro de 1999 até janeiro de 2010, que abordaram o componente auto-imune na ELA. Os bancos de dados pesquisados foram: Pubmed, Medline, Scielo e LILACS. As palavras-chave utilizadas foram: esclerose amiotrófica lateral; doenças auto-imunes e auto-imunidade nas línguas portuguesa, inglesa, espanhola e alemá.

Foram utilizados como critério de inclusão artigos com foco em modelos animais e estudos clínicos do tipo relato de caso, ensaios clínicos e de meta-análise. Os estudos de revisão foram avaliados para obtenção de artigos não encontrados na estratégia de busca. Os critérios de inclusão dos estudos foram: ser publicados de janeiro de 1999 até janeiro de 2010. Foram utilizados como critério de exclusão a não abordagem direta ao tema, a não disponibilidade do artigo e não se tratar de um artigo original.

\section{RESULTADOS}

Foram encontrados 50 artigos e, após os critérios de exclusão aplicados, resultaram em 11 artigos (Figura 1). Desses 11 artigos, 03 eram experimentais e 08 eram estudos em humanos.

\section{Estudos em animais}

Foram utilizados 3 trabalhos que tratavam de estudos experimentais em camundongos (Tabela 1).

Em 2000, um trabalho utilizou o IgG purificado de 10 indivíduos saudáveis, de 17 pacientes com ELA e 08 indivíduos controles (que possuíam outras co-morbidades exceto ELA, como síndrome de Guillain-Barré, síndrome de Lambert- Eaton, neuropatia motora e mieloma), e injetaram em camundongos fêmea balbC. Foram comparadas as anormalidades ultra-estruturais dos motoneurônios destes grupos e foi verificado que e a aplicação do IgG-ELA resultou em um maior acúmulo de 
Estudos que abordam componente auto-imune na ELA.

(n: 50)

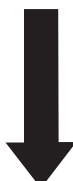

Estudos sobre auto-imunidade na ELA nas línguas portuguesa, inglesa e espanhola, de janeiro de 1999 a janeiro de 2010

(n: 38)

Estudos incluídos a partir de referências bibliográficas.

(n: 02)

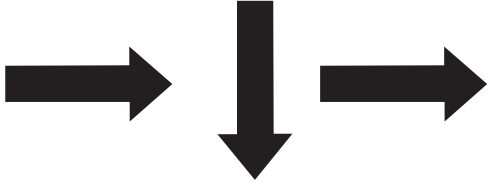

Estudos excluídos por não serem originais.

(n: 18)

\section{Estudos excluídos por não estarem disponíveis na íntegra.}

(n: 01)

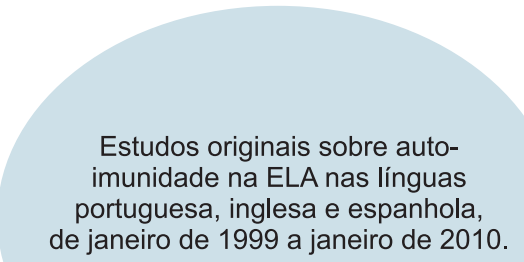

(n: 22)

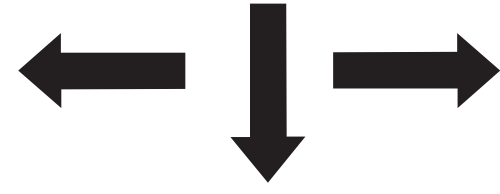

Estudos originais sobre auto-imunidade na ELA nas línguas

portuguesa, inglesa e espanhola, de janeiro de 1999 a janeiro de 2010 , disponíveis, avaliando critérios de inclusão e exclusão.

(n: 11)
Estudos excluídos por não se relacionarem ao tema.

(n: 10)

Figura 1. Busca em bancos de dados. 


\begin{tabular}{|c|c|c|c|c|}
\hline Autores & Ano & Estudo & Animal & Resultados \\
\hline Pullen e cols. ${ }^{6}$ & 2000 & Experimental & $\begin{array}{c}\text { Camundongos fêmea } \\
\text { balbC }\end{array}$ & $\begin{array}{c}\text { Camundongos com IgG -ELA: } \\
\text {-Mais anormalidades } \\
\text { ultraestruturais } \\
\text {-Maior depósito de cálcio }\end{array}$ \\
\hline Obal e cols. ${ }^{8}$ & 2001 & Experimental & $\begin{array}{c}\text { Camundongos macho } \\
\text { balbC }\end{array}$ & $\begin{array}{c}\text { Camundongos com IgG-ELA: } \\
\text { - Reaçáo da micróglia } \\
\text { - Não inicia resposta de célula T }\end{array}$ \\
\hline Clements e cols. ${ }^{9}$ & 2003 & Experimental & Ratos- SOD1 & $\begin{array}{c}\text { - Mutaçáa na micróglia levando } \\
\text { a degeneraçáo do neurônio }\end{array}$ \\
\hline
\end{tabular}

SOD1: enzima $\mathrm{Cu} / \mathrm{Zn}$ da Superóxido dismutase 1

cálcio nneurônios motores. Os camundongos expostos ao IgG-ELA desenvolveram mais anormalidades no neurônio motor do que os demais grupos, como a fragmentação e distensão do complexo de Golgi, lise mitocondrial e perda da organização dos corpos de Nissl. Estes camundongos também apresentaram um aumento na corrente e no influxo de cálcio para dentro do terminal sináptico e do motoneurônio ${ }^{6}$.

No estudo de 2001, foi realizada a injeção em quatro grupos de camundongos machos balbC, via intraperitoneal, de amostras da imunoglobulina purificada para verificar se a ativação da micróglia e a infiltração de linfócitos poderiam ser induzidas pela transferência direta da IgG dos pacientes com ELA. No grupo 1 os camundongos receberam a IgG de 5 pacientes com ELA (n: 15). No grupo 2 receberam a IgG de 5 pacientes com outras doenças como: esclerose múltipla, síndrome de Guillain Barré, doença de Parkinson, doença de Alzheimer (DA) e AVCi. (n: 15). O grupo 3 foi formado por camundongos que receberam a IgG de 3 cobaias tratadas com adjuvante total ou incompleto Freund(n: 9). Finalmente, o grupo 4 foi formado por camundongos que receberam a IgG de 3 cobaias com doença do neurônio motor imunomediada experimentalmente - EAGMD (n: 9). Nas secçóes do corno ventral dos segmento lombar da medula espinhal dos camundongos injetados com IgG- ELA foi observado elevado número de células da micróglia CD11b - imumonopositiva, como também nos camundongos que receberam a IgG das cobaias EAGMD. Os linfócitos CD3 não foram detectados no segmento lombar da medula espinhal dos camundongos com IgG -ELA ou IgG anti-motoneurônio das cobaias. Observou-se que o anticorpo IgG-ELA induz reação da micróglia no neurônio motor, mas sem iniciar resposta de célula $\mathrm{T}$ no camundongo receptor ${ }^{8}$.

Em 2003, um estudo utilizou 42 animais quiméricos, que são ratos com mosaicismo de células normais e células que expressam o polipeptídio mutante SOD1,para destacar a participação das células da micróglia na ELA. Observou-se que a localização da mutação iria influenciar na presença da doença, criando um micro-ambiente prejudicial ao neurônio, pois, um neurônio mutante está envolto por glia não-transgênica, os sintomas não se desenvolviam; enquanto que, se a mutação localiza-se somente na glia, este neurônio saudável e sem mutaçóes iria se degenerar.

\section{Estudo em humano}

Foram encontrados 8 trabalhos, sendo um relato de caso, 2 estudos caso-controle, 2 corte-transversal e 3 estudos descritivos (Tabela 2).

No estudo realizado em 2004 utilizaram-se da cultura primária de NM, a partir da medula espinhal de ratos, para definir as interaçôes envolvendo as células não neuronais (astrócitos e micróglia) e para investigar os efeitos das células da micróglia ativadas por lipopolissacarídeo (LPS) e imunocomplexos de IgG-ELA. Foram isoladas IgG de 6 pacientes com ELA (segundo os critérios do El Escorial) e 6 pacientes com doença controle ( neuropatia, doença de parkinson, DA, síndrome de Guillain Barré). A incubação da micróglia nos meios de cultura com $2 \mathrm{mg} / \mathrm{ml}$ de IgG-ELA ou $1 \mathrm{mg} / \mathrm{ml}$ de LPS in- 
Tabela 2

Artigos com estudos com humanos

\begin{tabular}{|c|c|c|c|c|}
\hline Autores & Ano & Estudo & Populaçáo & Resultados \\
\hline Zhao e cols. ${ }^{10}$ & 2004 & Descritivo & - 6 pacientes ELA & $\begin{array}{c}\text { - Os radicais livres da } \\
\text { ativação da micróglia podem } \\
\text { iniciar uma lesão no } \\
\text { motoneurônio }\end{array}$ \\
\hline Anneser e cols. ${ }^{11}$ & 2004 & Corte-tranversal & $\begin{array}{c}-5 \text { pacientes ELA } \\
\text { - } 5 \text { indivíduos saudáveis }\end{array}$ & $\begin{array}{c}\text { - Aumento dos receptores } \\
\text { de glutamato em pacientes } \\
\text { com ELA }\end{array}$ \\
\hline Pallotta e cols. $^{2}$ & 2009 & Descritivo & - 9 pacientes ELA & $\begin{array}{c}\text { - Aspecto reacional em } \\
100 \% \text { da MO dos } \\
\text { pacientes ELA } \\
\text { - Aumento de plasmócitos e } \\
\text { macrófagos }\end{array}$ \\
\hline Zhang e cols. $^{12}$ & 2004 & Caso-controle & $\begin{array}{l}\text { - } 38 \text { pacientes ELA } \\
\text { - } 28 \text { voluntários } \\
\text { - } 25 \text { pacientes DA }\end{array}$ & $\begin{array}{c}\text { - Aumento de TCD4 na } \\
\text { ELA e na DA } \\
\text { - Maior nível de IgG } \\
\text { na ELA } \\
\text { - Ativaçáo imunológica } \\
\text { sistêmica na ELA e DA }\end{array}$ \\
\hline Zhang e cols. ${ }^{13}$ & 2008 & Caso-controle & $\begin{array}{l}\text { - } 33 \text { pacientes ELA } \\
\text { - } 18 \text { saudáveis } \\
\text { - } 18 \text { pacientes DA }\end{array}$ & $\begin{array}{l}\text { - Aumento de LPS e da } \\
\text { ativaçáo dos monócitos/ma- } \\
\text { crófagos na ELA e DA }\end{array}$ \\
\hline Sengun e cols. ${ }^{14}$ & 2003 & Descritivo & $\begin{array}{c}\text { - } 20 \text { pacientes ELA } \\
-30 \text { pacientes com outras } \\
\text { doenças degenerativas }\end{array}$ & $\begin{array}{c}\text { - O sistema imune da ELA } \\
\text { é ativado pelo anticorpo } \\
\text { anti-Fas }\end{array}$ \\
\hline Offen e cols. ${ }^{15}$ & 1999 & Corte-trasnversal & $\begin{array}{l}\text { - } 19 \text { pacientes ELA } \\
-17 \text { indivíduos saudáveis }\end{array}$ & $\begin{array}{l}\text { - Presença de anticorpos } \\
\text { anti-canal de cálcio tipo-L } \\
\text { no soro dos casos }\end{array}$ \\
\hline Rao TV e cols. ${ }^{16}$ & 2004 & Relato de caso & - 01 paciente ELA & - ELA associada a LES \\
\hline
\end{tabular}

LES: Lupus Eritematoso Sistêmico

LPS: Lipopolissacarídeo

DA: Doença de Alzheimer

MO: Medula óssea

duziu alterações morfológicas na célula, como o aumento de corpos amebóides com vacúolos. Estas alteraçôes morfológicas foram acompanhadas do aumento drástico de secreção de TNF- $\alpha$ no meio depois do estímulo por 48hs com IgG-ELA e LPS ( $\mathrm{p}<0.01$ ). Observaram-se evidências que sugerem que os radicais livres liberados pela ativação da célula da micróglia podem iniciar uma lesão no neurônio motor que aumenta a susceptibilidade do receptor AMPA/kainato para os efeitos tóxicos do glutamato. Só que esta toxicidade pode ser bloqueada pelo antagonista do receptor AMPA/kainato ou pela adição do astrócito, o qual remove o glutamato do meio ${ }^{10}$.

Em outro estudo realizado em 2004 utilizaram amostras de tecido da medula espinhal de 5 pacientes com ELA, clinicamente diagnosticados segundo os critérios de El Escorial em provável ou definitiva ELA e 5 indivíduos controles. Utilizaram também amostras do líquido cefalorraquidiano (LCR) de 10 pacientes com ELA (que náo estavam em uso de medicaçáo) e 10 pacientes controles, que tinham dor de cabeça e foram avaliados para exclusão de hemorragia subaracnóidea, meningite, paralisia de Bells idiopática ou polineuropatia periférica idiopática. $\mathrm{O}$ estudo estabeleceu um modelo in vitro para testar o papel dos receptores metabotrópicos do glutamato (mGluR) na proliferação glial da ELA. Estes receptores estão envolvidos tanto na homeostase do glutamato quanto na proliferação glial. Através da hibridização in situ e da imunohistoquímica foi observado um aumento importante no grupo I e grupo II dos receptores de glutamato na medula dos pacientes com ELA quando comparados com os controles (mGluR5 $>$ mGluR1> mGluR2/3). Foi sugerido que a estimula- 
ção dos receptores metabotrópicos para o glutamato (mGLuR, localizado nas células da glia) por substâncias do líquor cefalorraquidiano contribuía para proliferação glial e astrogliose presentes na ELA ${ }^{11}$.

Em nosso estudo de 2009, analisamos amostras da medula óssea (MO) a partir da espinha ilíaca póstero-superior de 9 pacientes com ELA esporádica, que não possuíam processos inflamatórios, infecciosos, neoplásicos e alérgicos ( 7 do sexo masculino e 2 do feminino, com idade entre 38 e 61 anos). Quanto ao subtipo da ELA foram 5 do subtipo bulbar e 4, não bulbar. $\mathrm{Na}$ análise histológica a celularidade na MO estava preservada em 8 dos 9 casos. Plasmocitose foi encontrada em 100\% dos pacientes, o que indica ativação da proliferação de células B. Com a imunohistoquímica observou-se aumento de macrófagos (CD68+), bem como aumento de plasmócitos (VS38+) sendo estes policlonais. Os aspectos reacionais encontrados na MO de $100 \%$ dos pacientes reforçam a hipótese de que uma resposta imune sistêmica está presente em pacientes com ELA esporádica ${ }^{2}$.

Em 2004, novo estudo avaliou o plasma de 38 pacientes com ELA (12 mulheres e 26 homens, com a média de idade de 59,3 anos) e comparou com dois grupos controles: o primeiro formado por 28 voluntários (10 mulheres e 18 homens, média de idade 56 anos) e o segundo, por 25 pacientes com DA. Pacientes com ELA e com DA tiveram um aumento significante nos níveis de linfócitos T CD4 quando comparados com o grupo controle normal, como também aumento na ativação de monócitos/macrófagos. A imunidade humoral foi avaliada pelo nível de $\operatorname{IgG}$, o qual foi significantemente maior no grupo de pacientes de ELA. Demonstrou que uma ativação imunológica sistêmica tem papel ativo na ELA, assim como já foi demonstrado na DA. E que a ativação persistente de macrófagos e a expressão de HLA-DR e CD14 nestas células estão diretamente associadas com a taxa de progressão da doença. A ativaçáo e os marcadores de inflamação relacionados ao monócito ( HLA-DR e CD16) bem como a ativação das células $T$ dos pacientes com ELA podem fornecer valioso acompanhamento do tratamento da ELA como uma disfunção imune ${ }^{12}$.

O mesmo grupo realizou, em 2008, outro estudo com população similar para avaliar o papel imunológico da ELA. Utilizaram um grupo de 33 pacientes com ELA
(7 mulheres e 16 homens, média de idade 59,2 anos) e compararam com dois grupos controles: o primeiro com 18 indivíduos saudáveis ( 6 mulheres e 12 homens, média de idade 54,5 anos) e o segundo, com 18 pacientes com DA ( 11 mulheres e 7 homens, com média de 78,9 anos). Concentração aumentada da endotoxina LPS foi observada no plasma dos pacientes com ELA e com DA quando comparados aos indivíduos saudáveis e a concentração de LPS pode estar relacionado com o estágio da doença. Também foi detectado aumento na ativação dos monócitos ( HLA-DR) e este aumento foi diretamente relacionado a concentraçáo de LPS no plasma. Observou-se uma relação negativa entre o LPS no plasma e a intensidade da expressão da citocina IL-10 nos monócitos e macrófagos. O nível de LPS e a ativação dos monócitos/macrófagos podem estar relacionadas com a patogênese da ELA ${ }^{13}$.

Em 2003, realizaram um estudo para avaliar os títulos de anticorpo anti-Fas e o quanto este pode estar correlacionado com a progressáo da ELA. Utilizaram o soro de 52 pacientes com ELA esporádica e 9 pacientes com ELA familiar. Para o grupo controle estudaram o soro de 20 indivíduos saudáveis, 8 pacientes com doença de Parkinson, 7 pacientes com DA, 6 pacientes com atrofia multissistêmica e 1 paciente com degeneração da substância negra. $O$ valor acima de 17,34 ng/ul de anti-Fas foi considerado anormal. $25 \%$ dos pacientes com ELA esporádica e 22\% de ELA familial tiveram concentraçôes anormais do anticorpo. Metade dos pacientes que tinham doença de Parkinson também tinha concentraçóes anormais deste anticorpo, mas o mesmo não aconteceu com os pacientes com doença de Alzheimer. Não houve correlação entre os títulos de anti-Fas e a duração e estágio da doença.O sistema imune na ELA é ativado pelo anticorpo anti-Fas, mas observou-se que não é uma ativação exclusiva da ELA ${ }^{14}$.

Em 1999, realizaram um estudo de caso-controle, com 19 pacientes diagnosticados com ELA e outro grupo de 17 indivíduos, sendo 5 saudáveis e 12 com outra doença - não ELA, para avaliar a presença de anticorpos anti-canal de cálcio tipo L nos pacientes com ELA. Foi realizado um ensaio in vitro utilizando células PC12 para examinar a interação da IgG - ELA com o canal de cálcio tipo L. A secreção regulada de dopamina nas células PC12 é mediada pela entrada de cálcio através destes canais. Observou-se uma significativa inibição da liberação 
da dopamina pelo purificado da IgG dos pacientes com ELA (32\%) quando comparados com o controle (11\% dos pacientes com doença- não ELA e $9 \%$ dos indivíduos saudáveis). E também uma alta proporção de pacientes com ELA (79 \%) teve significativa inibição por IgG em comparação ao grupo controle (29\%) ( $<<0,01)$. O nível de inibição dos canais de cálcio pelo IgG-ELA correlacionam-se positivamente com a duração da doença e negativamente com a idade ${ }^{15}$.

Um grupo, em 2004, descreveu um caso de uma senhora omã de 27 anos, que há três anos apresentava história de fraqueza muscular esquelética progressiva, com alteraçôes clínicas e musculares compatíveis com ELA. Durante as investigaçóes da doença descobriram que ela tinha Lupus eritematoso sistêmico (LES). Estas duas doenças podem estar relacionadas, o que poderia explicar a patogênese da autoimunidade na $\mathrm{ELA}^{16}$.

\section{DISCUSSÃO}

A etiologia da auto-imunidade nas doenças humanas era baseada nos postulados de Koch, onde era necessária uma resposta auto-imune na forma de auto-anticorpo, imunidade mediada por células; e que através de experimentos animais o antígeno fosse identificado e que uma resposta imune análoga fosse induzida. Postulados recentes adicionaram a definição de linfócitos patogênicos mediando doença auto-imune ${ }^{17}$.

Três tipos de evidências devem conduzir a origem de uma doença à auto-imune: prova direta, prova indireta e prova circunstancial ${ }^{17}$.

\section{Prova Direta}

Evidencia a etiologia auto-imune de uma doença mediada por anticorpos após transferência direta de auto-anticorpo ${ }^{17}$. Alguns estudos, através da transferência da imunoglobulina purificada de pacientes com ELA, puderam comprovar que havia alteraçóes nos neurônios motores. Os 17 camundongos fêmea balbC que receberam a IgG - ELA apresentaram maior anormalidades estruturais e maior depósito de cálcio nos motoneurônios, quando comparados com os 18 controles. As alteraçôes degenerativas são efeitos secundários a entrada da $\operatorname{IgG}$ no neurônio, já que a IgG tem como alvo seletivo a subunidade $\alpha_{1}$ dos canais de cálcio voltagem dependentes. Desta forma, os aspectos morfológicos da hipótese auto-imune foram verificados, mas o modo como a IgG acessa o motoneurônio não foi elucidado ${ }^{6}$.

Através de outro estudo observou-se que a IgG de pacientes com ELA injetada em camundongos machos balbC não só induziram alteraçôes ultra-estruturais dos neurônios motores espinhais, mas também promoveram o recrutamento e ativação das células da micróglia. Esta ativação pode aumentar a lesão neuronal iniciada pela IgG através da formação de intermediários reativos de oxigênio. No entanto, a completa resposta imune pode não se desenvolver por causa da ausência de linfócitos CD3 nos motoneurônios dos camundongos estudados ${ }^{8}$.

Em um estudo da cultura primária de NM com células não neuronais (micróglia e astrócito), observou-se que quando a micróglia é ativada por imunocomplexo da IgG -ELA, esta célula contribui pra a lesão e morte do $\mathrm{MN}$ através da liberação de radicais livres ${ }^{10}$.

A prova direta pode ser comprovada também pela presença do anticorpo. No estudo de caso-controle com 19 pacientes com ELA e 17 controles, observou-se que o purificado da IgG - ELA interagia com o canal de cálcio tipo L, afetando a liberação de dopamina. A IgG -ELA apresentou um efeito significativo na liberação, mas nenhum efeito na recaptação de dopamina, o que sugere que o anticorpo é gerado especificamente contra o canal de cálcio tipo L. Os resultados comprovaram a presença do anticorpo na maioria dos pacientes com ELA e aventaram o mecanismo auto-imune na patogênese da ELA esporádica ${ }^{15}$.

Em estudo para analisar os títulos de anticorpo anti-Fas em 52 pacientes com ELA esporádica e 9 pacientes com ELA familiar observou-se concentraçóes anormais do anticorpo em um número considerável de pacientes. Apesar da ativação do sistema imune da ELA pelo anti-Fas não ser exclusiva, comprova a presença e a importância deste anticorpo na patogênese da doença. $\mathrm{O}$ anticorpo anti-Fas de pacientes com ELA induz a apoptose de células neuronais in vitro, o que corrobora a hipótese de mecanismo auto-imune através do auto-anticorpo anti- Fas na ELA ${ }^{14}$.

\section{Prova Indireta}

Evidencia a origem auto-imune da doença mediada por célula através da transferência de células $T$ pato- 
gênicas. Em estudo realizado com animais quiméricos observou-se que células não-neuronais selvagens poderiam aumentar a sobrevivência dos neurônios mutantes SOD1. O micro-ambiente neuronal é fundamental para a progressão da doença. Se a glia possui a mutação haverá o desenvolvimento da doença. Desta forma a ativação da micróglia pode levar a degeneração do neurônio e comprovar a doença auto-imune mediada por esta célula9.

Em outro estudo, o aumento significante na expressão dos receptores de glutamato nos pacientes com ELA evidenciou uma intensa proliferação glial e astrogliose. A disfunção glial e as interaçóes dos astrócitos ativados com a degeneração do motoneurônio podem estar presentes na patogênese da ELA ${ }^{11}$.

$\mathrm{O}$ isolamento de células $\mathrm{T}$ auto-reativas representa um dos principais alvos da doença auto-imune. O estudo que avaliou o plasma de 38 pacientes com ELA comparando com dois grupos de controles (28 voluntários e 25 com DA), evidenciou aumento dos níveis de linfócitos TCD4 + e ativação dos monócitos/macrófagos. Assim como também em outro estudo com população similar foi identificado esse aumento de monócitos. A ativação e os marcadores de inflamação relacionados ao monócito (HLA-DR e CD16) bem como a ativação das células $\mathrm{T}$ dos pacientes com ELA podem fornecer um valioso acompanhamento da ELA como disfunção imune ${ }^{12,13}$.

No nosso estudo realizado em 2009, ao se analisar amostras de tecido imunologicamente ativo foi observada uma imunoreatividade da MO em 100\% dos pacientes com ELA. A plasmocitose encontrada sugere a participação de células TH1 antígeno-específico, que leva a recrutação de células inflamatórias, ativação da micróglia e diferenciação dos linfócitos B em plasmócitos que produzem as imunoglobulinas. O papel da micróglia e da imunoglobulina na patogênese da ELA reforçam a hipótese de que uma resposta imune sistêmica está presente nos pacientes com ELA².

\section{Prova Circunstancial}

Algumas doenças são frequentemente designadas auto-imunes apesar de não preencherem um dos requisitos supra-citados, devido a: (1) presença de outra doença auto-imune no indivíduo ou alguém da mesma família, (2) infiltrado linfocítico no órgão-alvo, (3) associação estatística com um haplotipo do complexo maior de histocompatibilidade (MHC) específico, ou expressão aberrante de antígenos MHC classe I no órgão afetado, (4) resposta favorável à imunossupressão ${ }^{15}$. $\mathrm{O}$ relato de uma paciente omã que durante o diagnóstico de ELA foi identificado LES corrobora com a presença da autoimunidade na ELA já que a paciente possui uma doença já comprovadamente auto-imune ${ }^{16}$.

A ativação reacional da $\mathrm{MO}$ encontrada, no nosso estudo de 2009 , nos pacientes com ELA aventa a possibilidade da auto-imunidade, pois foi observado infiltrado de plasmócitos. Além disso, já é sabido que várias doenças auto-imunes possuem esta ativação reacional, como por exemplo na artrite reumatóide onde as células Th1 reagem contra o fator presente nas articulaçóes ${ }^{2}$.

\section{CONCLUSÃO}

Os achados dos estudos levantados constroem uma cadeia de evidências que determina a origem auto-imune da esclerose lateral amiotrófica esporádica. Novos estudos envolvendo auto-anticorpos e células T auto-reativas devem ser realizados. E a partir desta determinação da autoimunidade da ELA, novas estratégias terapêuticas podem ser traçadas.

\section{REFERÊNCIAS}

1.Rowland LP, Shneider NA. Amyotrophic lateral sclerosis. N Engl J Med 2001;344:1688-700.

http://dx.doi.org/10.1056/NEJM200105313442207

2.Pallotta R, Andrade A. Bone Marrow Immune Reactivity in Amiotrophic Lateral Sclerosis Patients. RBNP 2009;14:13-6.

3.Cluskey S, Ramsden DB. Mechanisms of neurodegeneration in amyotrophic lateral sclerosis. J Clin Pathol: Mol Pathol 2001;54:386-92.

4.Mitchell JD, Borasio GD. Amyotrophic lateral sclerosis. The Lancet 2007;369:2031-41.

http://dx.doi.org/10.1016/S0140-6736(07)60944-1

5.Bromberg MB. Pathogenesis of amyotrophic lateral sclerosis: a critical review. Curr Opin Neurol 1999;12:581-8.

http://dx.doi.org/10.1097/00019052-199910000-00012

6.Pullen AH, Humphreys P. Ultrastructural analysis of spinal motoneurones from mice treated with IgG from ALS patients, healthy individuals, or disease controls. J Neur Scienc 2000;180:35-45.

http://dx.doi.org/10.1016/S0022-510X(00)00427-5

7.Smith RG, Siklos L, Alexianu ME, Engelhardt JI, Mosier DR, Colom L, et al. Autoimmunity and ALS. Neurology 1996;47:40-6.

8.Obal I, Jakab JSK, Siklos L, Engelhardt JI. Recruitment of activated microglia 
cells in the spinal cord of mice by ALS IgG. Neuroreport 2001;12:2449-52. http://dx.doi.org/10.1097/00001756-200108080-00032

9.Clement AM, Nguyen MD, Roberts EA, Garcia ML, Boilée S, Rule M, Wild-type nonneuronal cells extend survival of SOD1 mutant motor neurons in ALS mice. Science 2003;302(5642):113-7. http://dx.doi.org/10.1126/science.1086071

10.Zhao W, Xie W, Le W, Beers DR, He Y, Henkel JS, et al. Activated Microglia Initiate Motor Neuron Injury by a Nitric Oxide and Glutamate-Mediated Mechanism J Neuropathol Exp Neurol 2004;63:964-77.

11.Anneser JMH, Chahli C, Ince GP, Borasio GD, Shaw PJ. Glial Proliferaton and Metabotrophic Gutamate Receptor Expression in Amyotrophic Lateral Sclerosis. J Neuropathol Exp Neurol 2004;63:831-40.

12.Zhang R, Gascon R, Miller RG, Gelinas DF, Mass J, Hadlock K, et al. Evidence for systemic immune system alterations in sporadic amyotrophic lateral sclerosis (sALS). J Neuroimmunol 2004;159:215-24.

http://dx.doi.org/10.1016/j.jneuroim.2004.10.009
13.Zhang R, Miller RG, Gascon R, Champion S, Katz J, Lancero M, et al. Circulating endotoxin and systemic immune activation in sporadic amyotrophic lateral sclerosis (sALS). J Neuroimmunol 2008;206:121-4. http://dx.doi.org/10.1016/j.jneuroim.2008.09.017

14.Sengun IS, Appel SH. Serum anti-Fas antibody levels in amyotrophc lateral sclerosis. J Neuroimmunol 2003;142:137-40.

http://dx.doi.org/10.1016/S0165-5728(03)00263-7

15.Offen D, Halevi S, Orion D, Mosberg R, Stern-Goldberg H, Melamed E, et al. Antibodies from ALS patients inhibit dopamine release mediated by Ltype calcium channels. Neurology 1999;52:1520-1.

16.Rao TV, Tharakan JK, Jacob PC. Systemic lupus erythematosus presenting as amyotrophc lateral sclerosis. Clin Nauropathol 2004;23:99-101.

17.Rose NR, Bona C. Defining criteria for autoimmune diseases (Witebsky's postulates revisited). Immunology Today 1993;14:426-30.

http://dx.doi.org/10.1016/0167-5699(93)90244-F 